\title{
Oncoplastic Approach to Giant Benign Breast Tumors Presenting as Unilateral Macromastia
}

\author{
Lekshmi Malathi ${ }^{1, \odot}$ \\ ${ }^{1}$ Department of Plastic Surgery, Government Medical College, \\ Kottayam, Kerala, India
}

Indian J Plast Surg:2020;53:439-441

\begin{abstract}
Address for correspondence Lekshmi Malathi, MS, MCh, DNB, Department of Plastic Surgery, Government Medical College, Gandhinagar, Kottayam-686008, Kerala, India (e-mail: jayakumar.lekshmi@gmail.com).
\end{abstract}

\begin{abstract}
Keywords

- giant benign tumors

- oncoplasty

- unilateral

macromastia

Benign breast tumors attaining large size constitute an important cause of unilateral macromastia. Their usual treatment involves enucleation or excision with a margin based on pathology and waiting for spontaneous retraction of skin envelope. In very large tumors, this will leave the residual breast deflated and unaesthetic, with spontaneous skin retraction giving unpredictable results. Application of the principles of oncoplastic surgery are helpful in this situation. Here, we present two cases of benign giant tumors-a giant fibroadenoma and a giant lipoma-managed by reduction mammaplasty approach to restore the breast symmetry and aesthetics.
\end{abstract}

\section{Introduction}

Symmetry is of utmost importance in paired organs such as breasts. The commonest cause of breast asymmetry or unilateral hypertrophy is an unequal physiological hypertrophy. However, a neoplastic etiology should be thought of when there is marked asymmetry or architectural distortion. ${ }^{1}$ The commonly encountered benign giant tumors are giant fibroadenoma, giant lipoma and benign Phyllodes tumor, and their preferred treatment involves enucleation for the first two and excision with a margin for Phyllodes tumor. When the asymmetry is significant, a simple enucleation or excision leaves behind a breast which is deflated, ptotic and unaesthetic. Waiting for spontaneous retraction of skin leads to unpredictable results, and some may need reoperation. Here, we present two cases-a giant fibroadenoma and a giant lipoma-which were managed through application of the principles of oncoplastic surgery, in order to achieve good aesthetic outcomes. These cases are being presented due to their rarity of occurrence and the reconstructive challenge involved in restoring breast symmetry and aesthetics.

\section{Case Report and Technique}

\section{Case 1}

A 34-year-old multiparous lady presented with right-sided macromastia for a period of 2 years. The enlargement was gradual and asymptomatic, except for a heavy feeling on the affected side. On examination, there was significant asymmetry and a few dilated veins over the affected breast. A firm mobile lump was felt in the most dependent part, which was reported as a benign epithelial proliferative lesion on fine needle aspiration cytology (FNAC). The patient was taken for a unilateral wise pattern reduction approach to enucleate the tumor, the markings of which are shown in - Fig. 1 a. A well-encapsulated tumor of $15 \times 13 \times 5 \mathrm{~cm}$ size and $650 \mathrm{~g}$ weight was removed, sparing parenchymal excision and with minimal skin excision ( - Fig. $1 \mathbf{b}$ ). The nipple areola complex (NAC) was transposed to the desired position as an inferior dermoglandular pedicle, and the medial and lateral limbs of the wise pattern were closed as an inverted " $T$ " over the remaining parenchyma. Since the patient did not want any modification of the contralateral breast, an attempt was made

\section{published online}

August 26, 2020
DOI https://doi.org/

$10.1055 / \mathrm{s}-0040-1716187$ ISSN 0970-0358.

\footnotetext{
(C) 2020. Association of Plastic Surgeons of India.

This is an open access article published by Thieme under the terms of the Creative Commons Attribution-NonDerivative-NonCommercial-License, permitting copying and reproduction so long as the original work is given appropriate credit. Contents may not be used for commercial purposes, or adapted, remixed, transformed or built upon. (https://creativecommons.org/licenses/by-nc-nd/4.0/).

Thieme Medical and Scientific Publishers Pvt. Ltd. A-12, 2nd Floor, Sector 2, Noida-201301 UP, India
} 
to recreate ptosis and position the NAC level with unoperated breast ( $\boldsymbol{- F i g . 1} \mathbf{c}$ ). The final histopathology was complex fibroadenoma. She had an uneventful postoperative period ( - Fig. 1 d). At 9 years follow-up, she retained good symmetry with no evidence of recurrence. Patient satisfaction was high despite a slightly elevated NAC on the operated side

\section{Case 2}

A 49-year-old obese, short statured lady came with hugely enlarged right breast for a period of 20 years. She noticed the asymmetry after her second childbirth, which was totally asymptomatic but gradually progressed. She sought medical help as the asymmetry became too obvious to be concealed by the traditional attire. On examination, there was a soft enlargement of the right breast with distortion and stretching of the NAC. A CT scan showed a well-encapsulated lesion with atrophic breast parenchyma, and FNAC and core biopsy reported fat cells only. We proceeded with a wise pattern reduction approach and enucleated a giant lipoma of size $21 \times 19 \times 7 \mathrm{~cm}$ weighing $1050 \mathrm{~g}$, occupying almost the entire breast. The NAC was repositioned as a superomedial pedicle this time. Since the breast parenchyma was very much atrophic, all the available skin, especially that in the lower part, was de-epithelized and tucked into the breast mound to achieve symmetry ( - Fig. 2 a-c). Since this patient also refused having any procedure on the unaffected side, an attempt was made to match the ptosis of the normal breast. The patient was asymptomatic and satisfied with the long-lasting good results at the end of

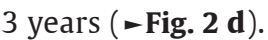

\section{Discussion}

Giant fibroadenomas are uncommon and account for 0.5 to $2 \%$ of all fibroadenomas. It is a rare variant having more than $5 \mathrm{~cm}$ size and a weight more than 500 g. $^{2}$ Complex fibroadenoma is a pathological diagnosis, having presence of one or more of the following features: sclerosing adenosis, papillary apocrine metaplasia, cyst $3 \mathrm{~mm}$ or larger, and epithelial calcification. ${ }^{3}$ They account for $16 \%$ of fibroadenomas, are usually smaller, and appear at an older age. Their malignant potential is variable in different studies. ${ }^{3,4}$

Lipomas are considered universal tumors and are not rare in the breast. They qualify as giant lipomas when the size is greater than $10 \mathrm{~cm}$ and weighs more than $1000 \mathrm{~g} .{ }^{1}$ Their malignant potential is very low, but diagnosis is often missed due to the indistinct consistency.

The treatment of a small- to medium-sized benign breast tumor is excision, and minor asymmetries get corrected by spontaneous retraction of skin. This is more so in a developing breast. But when there is a 20 to $50 \%$ volume loss, reshaping is needed to restore symmetry. ${ }^{5}$ Chepla et al described peri areolar techniques in adolescent patients with giant fibroadenomas, having good results at 1 year follow-up. ${ }^{6}$ In our series, both the patients were parous, with moderately ptotic breasts and a loose skin envelope. Hence, a dermoglandular pedicle with more freedom of adjusting NAC position was deemed suitable. Since both these patients refused modifying the normal breast, an attempt was made to mimic the ptosis and nipple position of the unaffected side

Oncoplasty, which is a blend of breast oncosurgery and plastic surgery, utilizes mainly three techniques-volume displacement, volume replacement and volume reduction. ${ }^{7}$ The volume displacement technique has been utilized in both these cases, where the available parenchyma and skin are rearranged to restore a symmetrical breast mound. In the second case, where there was significant parenchymal atrophy due to the long-standing nature of the lesion, the entire skin envelope outside the wise pattern is de-epithelized and used to auto-augment the breast like a "Goldilock's mastectomy," as described by Richardson and Ma. ${ }^{8}$ In this, skin sparing mastectomy done through wise incisions utilizes the
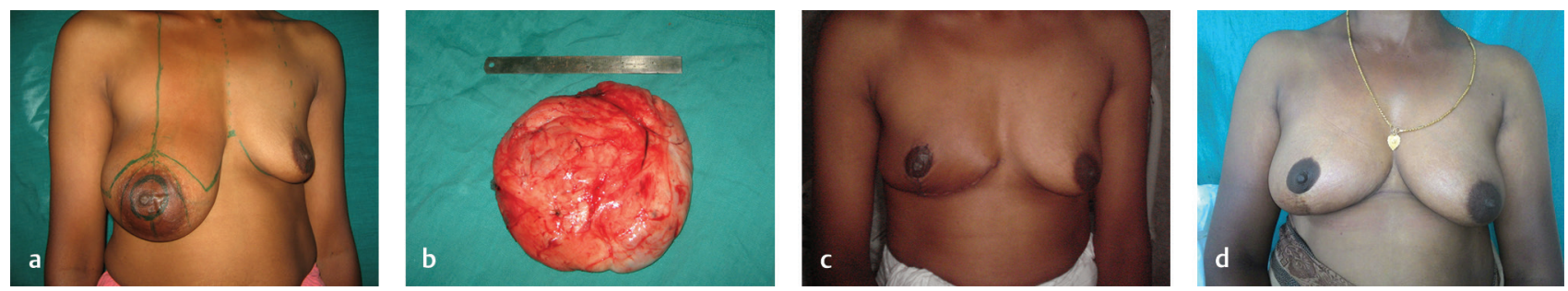

Fig. 1 (a) Case 1 with preop markings for excision. (b) Excised giant fibroadenoma. (c) 1-month postop result. (d) 9 years postop, with no recurrence and lasting symmetry.
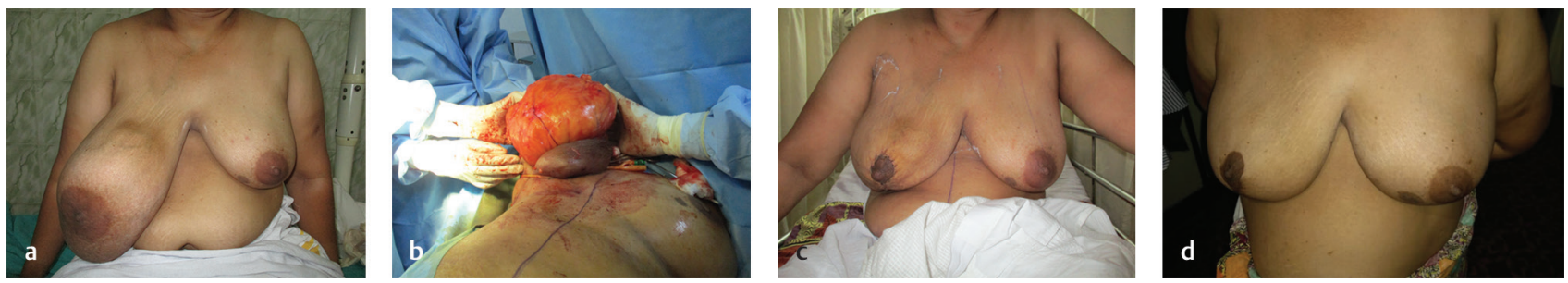

Fig. 2 (a) Case 2 preop. (b) Excision of the giant lipoma. (c) 1 week postop. (d) 3 years postop. 
residual cutaneous flaps to auto-augment the breast mound. ${ }^{9}$ Despite minor discrepancies in NAC levels in both cases, longterm symmetry and patient satisfaction were excellent

\section{Conclusion}

Management of benign breast tumors requires elimination of the pathology, with restoration of the form and function. The above two cases exemplify the successful application of oncoplastic surgery in managing benign breast tumors, presenting as unilateral macromastia and producing lasting results.

\section{Note}

This article has been prepared after obtaining necessary patient consent and ethical clearance from the institution.

This was presented as an e-paper at APSICON 2017, New Delhi.

\section{Disclosure}

No financial disclosure to be made by the author.

\section{Conflicts of Interest}

None declared.

\section{Acknowledgment}

I am thankful to both my patients who readily consented for using their photographs for this article and willingly took the strain to come for a late follow-up. My heartfelt gratitude to my teacher Prof. Saramma Varghese for her valuable guidance during the first case.

\section{References}

1 Ramírez-Montaño L, Vargas-Tellez E, Dajer-Fadel WL, Espinosa Maceda S. Giant lipoma of the breast. Arch Plast Surg 2013;40(3):244-246

2 Sharma S, Rana BP. Giant fibroadenoma of breast: a diagnostic dilemma in a middle aged woman. Adv Cytol Pathol 2017;2(4):109-112

3 Sklair-Levy M, Sella T, Alweiss T, Craciun I, Libson E, Mally B. Incidence and management of complex fibroadenomas. AJR Am J Roentgenol 2008;190(1):214-218

4 Dupont WD, Page DLPF, Parl FF, et al. Long-term risk of breast cancer in women with fibroadenoma. N Engl J Med 1994;331(1):10-15

5 Chirappapha P, Lertsithichai P, Sukarayothin T, Leesombatpaiboon M, Supsamutchai C, Kongdan Y. Oncoplastic techniques in breast surgery for special therapeutic problems. Gland Surg 2016;5(1):75-82

6 Chepla KJ, Armijo BS, Ponsky TA, Soltanian HT. Benefits of immediate dermoglandular preserving reconstruction following giant fibroadenoma excision in two patients. J Plast Reconstr Aesthet Surg 2011;64(9):e244-e247

7 Rose M, Svensson $\mathrm{H}$. The concept of oncoplastic breast surgery applied in surgery for a giant fibroadenoma. Case Reports Clin Med 2014;3(April):207-210

8 Richardson H, Ma G. The Goldilocks mastectomy. Int J Surg 2012;10(9):522-526

9 Schwartz JC. Goldilocks mastectomy: a safe bridge to implantbased breast reconstruction in the morbidly obese. Plast Reconstr Surg Glob Open 2017;5(6):e1398 